\title{
Three Typed Pragmatics for Dialogue Structure Analysis
}

\author{
Hitoshi IIDA*, Takayuki YAMAOKA* and HidekazuARITA** \\ * ATR Interpreting I'elephony Research Laboratories \\ Sanpeidani, Inuidani, Seika-cho,Souraku-gun, Kyoto 619-02, Japan \\ [\{iida/yamaoka\}\%atr-la.atr.co.jp@uunet.UU.NEI] \\ ** Mitsubishi Electoric Corporation \\ 8-1-1 T'sukaguchi-honmachi, \\ Amagasaki, Hyougo 661, Japan \\ [arita\%sys.crl.melco.junet@uunet.UU.NE']
}

\begin{abstract}
An experimental system for dialogue structure analysis based on a new type plan recognition model for spoken dialogues has been implemented. 'This model is realized by using four typed plans which are categorized into three kinds of universal pragmaties and a kind of taskdependent knowledge related to common action hierarchies. 'The experimental system is characterized by higher modularity and computational efficiency through defining a hierarchical usage order between these knowledges. The system can grasp a dialogue structure making it possible to solve problems related to spoken dialogue interpretation.
\end{abstract}

\section{INTRODUCTION}

An efficient and smooth communicalion between humans is generally realized in spoken dialogues. This fact is mainly supported by various ellipsis expressions concerning ofd information, the dialogue participants, zeropronouns - especially in Japanese, substitutional verbs and so on. $\Lambda$ s a result, each utterance is fragmental. A sequence of these utterances generally construct a whole dialogue step by step. Fragmental utterance comprehension by a hearer can be achieved using knowledge of the dialogue sibution, context information, domain dependent knowledge, especially the domain dependent action hierarchy[Litman 87], universal pragmatics concerning how to advance a dialogue, maintain dialogue cooperation between dialogue participants, etc., and language specific pragmatics [Levinson83]. Such ellipsis resolution is one of the main problems in discourse understanding. Several approaches were proposed and implemented in lllendrix78], [Shimazu79], [Carbonell83], etc. These researchers used various heuristic rules and did not make a clear distinction between domain specifie knowledge and pragmatics. As a consequence, the user interface became inflexible because the system basically handled expected utterance patterns.

*(1) :A discourse goal is characterized by a discourse expectation which dialogue participants mutually believe as an expectation. Therefore, a discourse goal is very vague because a expectation depends on various attentions or empathies and the participant's knowledge.

*(2): Allowing embedded turn-takings.

* (3) : A communicative act is basically defined as an abstract action, one that effects the hearer's thinking or decision-making and which can be described by a plan schema (cf. Cohen84).
Recently, a plan-based dialogue understanding approach was developed using a kind of pragmatics metaplan: a 'discourse plan' incorporated with domain knowledge, 'domain plan'[Litman87]. 'This approach was based on Allen \& Perrault's plan recognition strategies [Allen80], [Perrault80], [Allen87]. By way of contrast, a pragmalic-based approach was proposed in order to understand intersentential elliptical fragments [Carberry891. She claimed Litman's strategies could not recognize a surprise or a doubt conveyed by an elliptical fragment, for example " $\$ 10,000$ ?", which is not a complete sentence including postulated speech acts 'request' or 'inform'. In addition, she also claimed that metaplans representing communicalive goals should be dealt with adequately. She newly introduced 'discourse expectation' rules for grasping interaction between an information-seeker and an information-provider and 'discourse goal' rules for identifying an information-seeker's conversational or communicative goal*(1). 'lhese rules are heuristics for interpreting an elliptical fragment which explicilly indicates no linguistic clues to interpreting speech acts. On the other hand, in order to make the general understanding mechanism clear, a surprise or a doubt fragment such as mentioned above, must be understood from recognizing an irregular meaning from the view of gaps belween common sense (a certain prerequisite condition) and the declaration. Furthermore, studying how to express a query, an answer, a confirmation, a surprise or a doubt in a context and a dialogue situation is necessary.

In consideration of making a dialogue understanding model including such an understanding process, a method to handle pragmatics and utterance or dialogue must be studied. This paper shows three typed pragmatics used for cooperative dialogue development, as well as a dialogue structure analysis and understanding model using a plan recognition approach. 'The pragmatics are described by a 'dialogue plan', 'communication plan' and 'interaction plan'.

\section{THREE TYPED PRAGMATICS}

Three types of universal pragmatics (cf. Levinson83) can be classified and described by the following plans: Interaction. Plan - a plan basically characterized by a dialogue turntaking*(2) which describes a sequence of communicative acts*(3), Communication-Plan a plan which delermines how to execute or 
achieve an ullerance goal or dialogue goals, and Dialoguellan : a plan for establishing a dialogue construction, e.g. a cooperative dialogue* $(4)$.

For example, in order to achieve the goal of registering for the conference the following sequence must usually be performed (DomainPlanj: obtain a registration form, fill out the form and return it to the secretariat. In such a telephone dialogue, if something is needed to execute the goal action, a request to send it can be made, or it will be offered to you (Communication-Plan). To complete the cooperative information-secking, the hearer will respond to the speaker's request*(5) (InteractionPlan). Belore building a whole dialogue structure, the speaker should utter the opening section of the dialogue, especially on the telephone. Furthermore when the dialogue is finished, the speaker should wide up the dialogue (Dialogue-Plan).

Liach plan is described in terms of a schema formulation (plan-schema).

A plan-schema has various slots to describe both an action's inner properties, e.g. HEADER and PREDICATE\&CASES, and relationships between the action and prerequisite states/actions, effects, etc., e.g. PREREQUISITL, DECOMPOSITIONS, CONSTRAIN'IS, EFIECIS.

$A$ definite hierarchical order among these plans is available as follows;

Interaction-Plan > Communication-Plan $>$

Domain-Plan > Dialogue-Plan.

\section{DIALOGUE ANALYSIS}

There are several linguistic phenomena which are hard to interpret, such as ellipses, referring pronouns and substitutional expressions. Both information from the established context and expectations from the current dialogue situation are required to resolve such problems. In order to get these information a dialogue structure which indicates the goal hierarchy of utterances in a dialogue must be constructed. A dialogue analysis is required and it is necessary to determine;

(1) how to infer each goal of an utterance within a dialogue,

(2) how to make clear the relationships between goals within the dialogue.

For the first problem, a plan recognition inference method is adequate for identifying an utterance intention because the intention can be inferred by recognizing the speaker's plan by chaining communicative acts regarded as speech acts in a specific domain [Allen80], [Perrault80], [Litman 87]. For the second problem, the

\footnotetext{
*(4): A dialogue global construction usually has an opening section and closing section. Here, such a linguistic phenonenon is regarded as language-universal. *(5): On the other hand, in order to complete the cooperative interaction, when the speaker imparts information, the hearer vill confirm what the speaker has said according to the speaker's belief in the hearer's intention.

*(6) An active chart parser has been developed for Japanese dialogue analysis on a unification based grammar, which is based on HPSG and JPSC [Pollard88], [Gumji87], [Kogure89]. Furthermore, many discourse entities can be identified by using NP Identification Method [Nogaito88]
}

domain-specilic knowledge is related to the action and objects, especially the action hierarchy which is used to grasp the utterance goal, and three kinds of pragmatics between humans involved in a spoken dialogue are used to grasp the dialogue development.

\subsection{Communicative Acts}

First, in order to recognize the speaker's plan, it is necessary to recognize the turn-taking patterns. Communicative acts [Cohen84] are introduced. In lig. 1, an example of communicative acts in a cooperative taskoriented dialogue, e.g. 'queries and explanations regarding registration for an international conference' is shown.

A communicalive act in the demand class and a corresponding act in the response class make a turn-taking pair. 'This is recognized by the interaction plan. A communicative act is a decomposition element of an interaction plan.

\begin{tabular}{|c|c|}
\hline Demand Class & Response Class \\
\hline $\begin{array}{l}\text { Ask-value } \\
\text { "When is the deadline?" }\end{array}$ & $\begin{array}{l}\text { Inform-value } \\
\text { "lhe deadline for the } \\
\text { paper is June } 3 . "\end{array}$ \\
\hline $\begin{array}{l}\text { Confirm-value } \\
\text { "The deadline is dune } 3 \text {, isn't it?" }\end{array}$ & $\begin{array}{l}\text { Amirmative } \\
\text { "Yes, it is." } \\
\text { Negative } \\
\text { "No, it isn't." }\end{array}$ \\
\hline $\begin{array}{l}\text { Request-action } \\
\text { "Will you send me the form?" }\end{array}$ & $\begin{array}{l}\text { Accept } \\
\text { "OK" } \\
\text { Reject } \\
\text { "I'nu afraid I can't." }\end{array}$ \\
\hline $\begin{array}{l}\text { Give-olfer } \\
\text { "Shall I send you the form?" }\end{array}$ & $\begin{array}{l}\text { Accept-offer } \\
\text { "Yes, please" } \\
\text { Rejectorrer } \\
\text { "No, thank you." }\end{array}$ \\
\hline
\end{tabular}

Fig 1 An Example of Communicative Acts

\subsection{Inference Mechanism}

An utterance meaning is represented by illocutionary speceh act types and propositional contents oblained from a Head-Driven unification-based active chart parser*(6) for Japanese dialogues. The parsing result is described by a feature structure and the system input is modified into a communicative act with propositional contents. These consist of a certain predicate, an 'utterance type', and some variables, in particular, 'speaker', 'hearer', and 'topic'. 'Tlopic' is, on a surlace level, an NP marked with the Japanese special particle, 'wa', or the compound particle 'nituite'.

'I'he plan recognizer (1) assumes a goal. (2) If a particular goal cannot be found, then stop else goto next (3). (3) Infer a chaining path from an input to the goal. If success, stop. Else return to the first process (1) in order to try to find the next candidate. The chaining process between plans generally finds a candidate plan from the current state (HEADER) to an action list represented in DECOMPOSITION. However if this fails, the chaining will be continued in accordance with PREIREQUISITE and EF FECT.

In order to manage the current understanding state, the system uses two stacks. UNDERSTANDING-LIST stores completed plans as the current understanding state, and GOAL-LIS'l maintains incomplete plans regarded as possibilities and expectations for 
future goals. An overview of a dialogue structure construction process is shown in Fig. 2 .

\section{AN EXPERIMENTAL SYSTEM}

This analysis model is realized by using four lyped plans which are categorized into three types of universal pragmatics and a type of taskdependent knowledge related to common action hierarchies. The system has been implemented in Symbolics Common Lisp. A dialogue structure is represcnted by both completed plans and incomplete plans stored in the two stacks. Therefore, the system can understand dialogue meanings and can offer a dialogue structure using the contents of both stacks. Four model dialogues regarding an international conference registration taken from slightly modified inter. keyboard dialogues in Japanese have been applied. For example, the system can understand a Japanese substitutional expression, e.g. "Oisog-i kudasai" (literal translation : 'Hurry please') which shows no agent, no object and no verb, because the current topic which is focused on an action in the domain plan is known in the system and the omitted verb (e.g. 'Return-Form') can be identified under the scope dominated by the topic.

\section{CONCLUSION}

Litman \& Allen introduced a sel of discourse plans, each one corresponding to a particular way that an utterance can relate to a discourse topic. 'They distinguish discourse plans from a set of domain plans. The dialogue structure analysis model basically follows the above idea and uses new three typed pragmatics: interaction plan, communication plan and dialogue plan. By introducing these plans, the mechanism for constructing a dialogue structure becomes clear because of the way a surface utterance is connected with both pragmatics and the domain-specific knowledge, and by reducing the search space using a hierarchical order of applying knowledge, computational efliciency is improved.

\section{Acknowledgement}

The authors would like to thank The President Dr. Akira Kurematsu and our other colleagues at A'TR Interpreting Telephony Research Laboratories for their encouragement and thought-provoking discussions.

\section{REFERENCES}

[Allen 80] Allen, J. F. and Perrault, C. R. : Analyzing Intention in Utterances,

Artificial intelligence, Vol.15, pp143-178(1980).

[Allen 87] Allen, J. F. : Natural Language Understanding, The Benjamin/Cummings Publishing Co. (1987).

[Carberry 89] Carberry, S. : A Pragmatics-Based Approach to Ellipsis Resolution,

Computational Linguisties, Vol.15, No,2, pp75-96(1989).

[Carbonell 83]Carbonell, J. : Discourse Pragmatics and Eilipsis Resolution in Task-Oriented Natural Language Interfaces, 21 st Annual Meeting of the ACL,pp164168(1983).

[Cohen 84] Cohen, P. R. : The Pragmatics of Referring and Modality of Communication, Computational Linguistics, Vol.10, No.3, pp97-146(1984).

[Hendrix 78] Hendrix, G. G. et al. : Developing a Natural Language Interface to Complex Data, ACM 'Trans, Vol.3, No.2, pp 105-147(1978)

[Gunji 87] Gunji, T, : Japanese Phrase Structure Graminar, Dordrecht, D. Reidel (1987).

[lida 89] lida, H. et al. : An Experimental Spoken Natural Dialogue Translation System Using a Lexicon-Driven Grammar, European Conference on Speech Comınunications and Technology (1989).

[Kogure 89] Kogure, K. : Parsing Japanese Spoken Sentences Brased on HPSG,

the Int. Workshop on Parsing Technologies (1989).

[Levinson 83] Levinson, S.' C. : Pragmatics, Cambridge University Press (1983).

[Litman 87] Litman, D: J. and Allen, J. F. : A Plan

Recognition Model for Subdialogues in Conversations, Cognitive Science, Vol.1 1, pp163-200 (1987).

[Nogaito 88] Nogaito, 1. and Iida, 11. : Noun Phrase Identification in Dialogue and its Application, 2 nd International Conf. on Theoretical and Methodological Issues in Machine Translation of Natural Language (1988).

[Perrault 80] Perrault, C. R. and Allen, J. F. : A Plan-Based Analysis of Indirect Speech Acts, Computational Linguistics, Vol.6, pp 166-182(1980).

[Polard 89] Pollard, C. and Sag, I. : Information-Based Syntax and Semantics - Vol.1 Fundamentals, CSLL Lecture Notes, No.13 (1988).

[Shimazu 79] Shimazu, $\Lambda$. and Iida, II. : Experimental Japanese Language Question Answering System MSSS78, 6 th International Joint Conf. on AI, pp803-808 (1979).

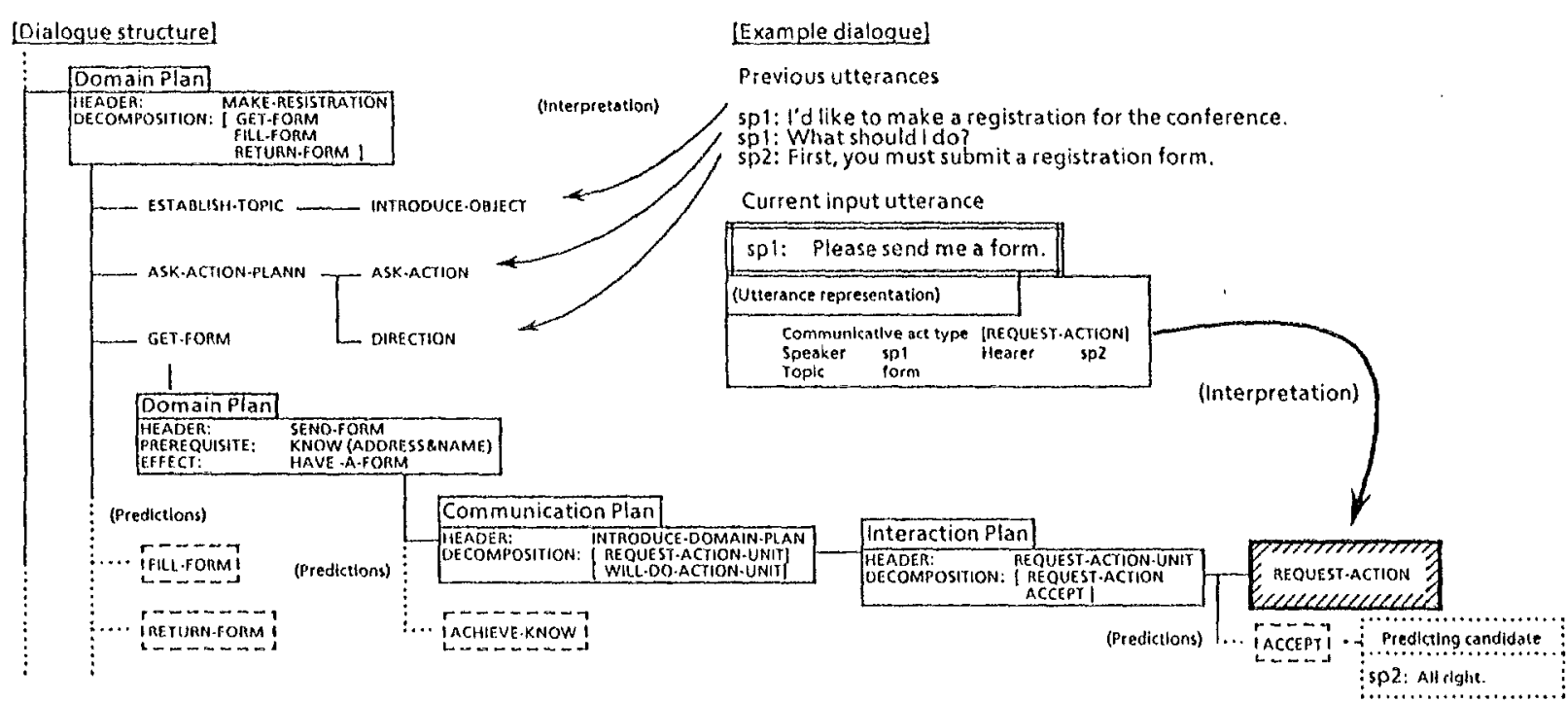

Fig.2 An Overview of a Dialogue Structure Construction Process 